\title{
Model tata kelola dan supply chain sampah saat pandemi covid- 19 di Kepulauan Seribu
}

\section{Waste management and supply chain models during the COVID-19 pandemic in the Thousand Islands}

\author{
I. Y. Adiningsih ${ }^{1 *}$, S. Almayna1, L. E. Silaban², R. Afiana1 \\ ${ }^{1}$ Departemen Ekonomi Sumberdaya dan Lingkungan, IPB University, Bogor, Indonesia \\ 2Departemen Ilmu Ekonomi, IPB University, Bogor, Indonesia
}

\begin{abstract}
Abstrak.
Kepulauan Seribu merupakan salah satu kabupaten di DKI Jakarta, Indonesia. Kepulauan Seribu memiliki tata kelola sampah yang berbeda dibandingkan dengan yang ada di darat, karena harus mengirimkan sampah melewati laut. Tujuan penelitian ini adalah untuk mengetahui model tata kelola dan supply chain sampah di Kepulauan Seribu dengan: (1) Menganalisis kondisi sampah di Kepulauan Seribu saat pandemi Covid-19, (2) Menganalisis supply chain sampah di Kepulauan Seribu saat pandemi Covid-19, (3) Menganalisis model dan strategi pengelolaan dan pengolahan sampah yang efektif di Kepulauan Seribu. Metode yang digunakan adalah metode analisis deskriptif, metode analisis supply chain, dan metode analisis SWOT. Hasil penelitian menunjukkan bahwa sudah ada tata kelola sampah yang baik di Kepulauan Seribu yang ditunjukkan dengan sudah adanya berbagai kebijakan dan tata aturan yang tertulis dari pemerintah untuk pengelolaan sampah. Namun, terdapat beberapa kendala seperti terbatasnya jumlah transportasi untuk mengirimkan sampah dan faktor cuaca yang terkadang menghambat pengiriman sampah ke Bantar Gebang. Hasil analisis SWOT menunjukkan bahwa kondisi pengelolaan sampah di Kepulauan Seribu berada pada kuadran I, Hal artinya pengelolaan tersebut mendukung strategi yang agresif.
\end{abstract}

Kata kunci: Kepulauan Seribu, supply chain, SWOT, tata kelola sampah

\begin{abstract}
.
Thousand Islands is one of the districts in Jakarta Capital Special Region, Indonesia. Thousand Islands has a different waste management to those on land, because the waste must be shipped by sea. The purpose of this study was to determine the management model and supply chain of waste in Thousand Islands by: (1) Analyzing the condition of waste in Thousand Islands during the Covid-19 pandemic, (2) Analyzing the waste supply chain in Thousand Islands during the Covid-19 pandemic, (3) Analyzing models and strategies for effective waste management and processing in Thousand Islands. The method used was descriptive analysis method, supply chain analysis method, and SWOT analysis method. The results of this study indicate that Thousand Islands already has good waste management which is indicated by the existence of various written policies and regulations from the government for waste management. However, there are several obstacles such as the limited amount of transportation to send waste and weather factors that sometimes hinder the delivery of waste to Bantar Gebang. The results of the SWOT analysis show that the condition of waste management in Thousand Islands is in quadrant I, its means the management supports an aggressive strategy.
\end{abstract}

Keywords: Thousand Islands, supply chain, SWOT, waste management

\section{PENDAHULUAN}

Kepulauan Seribu merupakan suatu kabupaten di Daerah Khusus Ibukota (DKI) Jakarta dengan luas wilayah $8,70 \mathrm{~km}^{2}$ yang terbagi atas 2 kecamatan dengan 6 kelurahan dan 110 pulau. Jumlah penduduk Kepulauan Seribu sebanyak 27.750 jiwa yang tersebar di 11 pulau diantaranya Pulau Untung Jawa, Pari, Lancang, Tidung Besar, Tidung Kecil, Pramuka, Panggang, Harapan, Kelapa, Kelapa Dua, dan Sebira (BPS 2021). Keindahan Kepulauan Seribu menarik para wisatawan untuk berkunjung. Hingga saat ini Kepulauan Seribu masih menjadi destinasi wisata alam yang menarik untuk dikunjungi para wisatawan.

\footnotetext{
*Korespondensi Penulis

Email : intanyunianti@apps.ipb.ac.id
} 
Keunikan Kepulauan Seribu yang dipenuhi oleh aktivitas penduduk setempat, ditambah pantai dan laut yang membentang luas sehingga dipenuhi oleh kegiatan para wisatawan membuatnya perlu memiliki pengelolaan sampah yang lebih kompleks dibandingkan dengan pengelolaan sampah di darat. Sampah dianggap sebagai salah satu masalah lingkungan paling serius yang dihadapi daerah perkotaan di negara berkembang (Premakumara et al. 2011). Sumber sampah berasal dari penduduk pulau dan luar pulau. Salah satu jenis sampah yang berbeda dari sampah daratan adalah marine debris. Marine debris atau sampah laut didefinisikan sebagai bahan padat yang diproduksi atau diproses secara terus-menerus yang dibuang atau ditinggalkan di lingkungan laut dan pesisir. Lima kategori utama sampah laut terdiri dari plastik, kertas, logam, tekstil, kaca dan karet (Agamuthu et al. 2019). Berdasarkan penelitian yang dilakukan oleh Pusat Penelitian Oseanologi-LIPI, Kepulauan Seribu menerima sampah dari luar pulau melalui 13 sungai yang bermuara di Teluk Jakarta (Sahwan 2004). Seiring dengan bertambahnya populasi, sampah menjadi hal yang penting untuk diatasi (Suhada and Al-Mahdy 2020). Sampah adalah persoalan dunia, karena pertumbuhan penduduk dan produksi penduduk dunia terus meningkat, sehingga meningkatkan jumlah sampah dan membuat tempat pembuangan akhir sampah menjadi lebih banyak dan merusak lingkungan (Skenderovic et al. 2015).

Saat pandemi Covid-19, sampah di Kepulauan Seribu menunjukkan angka penurunan, hal ini terjadi akibat penurunan jumlah wisatawan yang berkunjung. Namun, berbeda dengan sampah kiriman yang justru meningkat diakibatkan oleh packaging hasil kegiatan belanja online masyarakat. Adapun upaya pengelolaan sampah masih dilakukan oleh Suku Dinas Lingkungan Hidup (Sudin LH) Kepulauan Seribu, baik secara institusional maupun kolektif dengan mengajak masyarakat, instansi swasta, dan perangkat daerah terkait, serta melakukan upaya pengelolaan sampah di tingkat rumah tangga yang lebih intensif seiring dengan pemberlakuan PerGub Provinsi DKI Jakarta Nomor 77 Tahun 2020 tentang pengelolaan sampah di lingkup rukun warga (RW). Pencapaian pengurangan sampah Kepulauan Seribu adalah terbentuknya 24 bank sampah binaan yang didampingi langsung oleh Sudin LH Kabupaten Administrasi Kepulauan Seribu yang sudah mereduksi sejumlah $217.627 .38 \mathrm{~kg}$ sampah ekonomis sejak Januari hingga Oktober 2020, serta menurut Sudin LH, penanganan sampah di pesisir kepulauan pada tahun 2020 sudah jauh lebih baik dengan kapasitas jumlah yang terangkut sudah bertambah 9 ton setiap harinya (Baidowi et al. 2020).

Permasalahan pengelolaan sampah di Kepulauan Seribu adalah terkait jumlah kapal serta fasilitas penunjang pengelolaan sampah lainnya seperti jumlah kendaraan pengangkut sampah yang terbatas, serta kapasitas 
pembuangan akhir sampah yaitu Tempat Pembuangan Sampah Terpadu (TPST) Bantar Gebang yang diprediksi akan mencapai jumlah maksimum pada tahun 2021 ini (Putri et al. 2020). Bantar Gebang memiliki luas sekitar 12,4 ha, dengan 4 dari 5 zona telah ditutup karena beban sampah telah menumpuk seluas 10 ha (Kholil et al. 2018). Tentu hal ini sangat mengkhawatirkan, karena sampai saat ini TPST Bantar Gebang masih menjadi tempat pembuangan akhir sampah satusatunya bagi wilayah DKI Jakarta, Bekasi dan Kepulauan Seribu. Oleh karena itu, melalui penelitian ini ingin dianalisis kondisi sampah di Kepulauan Seribu saat pandemi Covid-19, analisis supply chain sampah di Kepulauan Seribu saat pandemi Covid-19, dan analisis model dan strategi pengelolaan dan pengolahan sampah yang efektif di Kepulauan Seribu.

\section{METODOLOGI}

\subsection{Lokasi kajian dan waktu penelitian}

Penelitian dilaksanakan secara daring dan luring selama Juni-September 2021 di Kepulauan Seribu tepatnya di Pulau Tidung. Pemilihan lokasi tersebut dilakukan secara sengaja (purposive sampling) dengan pertimbangan bahwa jumlah penduduk di pulau tersebut semakin meningkat dan aktivitas masyarakat saat pandemi Covid-19 di lokasi tersebut akan berpengaruh terhadap jumlah sampah yang dihasilkan.

Data primer dan sekunder dikumpulkan dalam penelitian ini. Berbagai teknik pengumpulan data primer dilakukan yaitu wawancara (secara daring dan luring), Focus Group Discussion, dan lainnya. Wawancara secara daring dilakukan terhadap stakeholders yang mempunyai wawasan luas tentang tata kelola sampah di Kepulauan Seribu, antara lain lurah di Kepulauan Seribu, Kepala Suku Dinas Lingkungan Hidup (DLH), Penyedia Jasa Lainnya Orang Perorangan Lingkungan Hidup (PJLP LH) di Kepulauan Seribu, Yayasan Jejak Seribu, NonGovernmental Organization (NGO) Divers Clean Action, dan stakeholders yang mempunyai wawasan di daerah bagian hilir yaitu Kepala Staf TPST Bantar Gebang.

\subsection{Prosedur analisis data}

Analisis deskriptif kualitatif (untuk membahas tujuan ke-1). Selanjutnya, untuk membahas tujuan ke-2 digunakan analisis supply chain (Rantai Pasok). Terakhir, untuk membahas tujuan ke-3 digunakan analisis SWOT, yang merupakan akronim dari Strength (kekuatan), Weakness (kelemahan), Opportunities (peluang) dan Threat (ancaman). Dari beberapa elemen SWOT maka dapat dilakukan analisa yang lebih mendalam agar menciptakan luaran yang bermanfaat bagi masyarakat, pemerintah, dan lingkungan. 


\section{HASIL DAN PEMBAHASAN}

\subsection{Kondisi sampah di Kepulauan Seribu saat pandemi covid-19}

Kepulauan Seribu terletak di Provinsi DKI Jakarta yang mempunyai luas daratan $8,76 \mathrm{~km}^{2}$ dan luas lautan $4.690,85 \mathrm{~km}^{2}$, serta mempunyai 110 pulau dengan hanya 11 pulau yang berpenghuni. Pengelolaan sampah di Provinsi DKI Jakarta diatur dalam PerDa Provinsi DKI Jakarta Nomor 13 Tahun 2013 yang kemudian direvisi menjadi PerDa Provinsi DKI Jakarta Nomor 4 Tahun 2019. Turunan dari PerDa tersebut yaitu:

1. PerGub Provinsi DKI Jakarta Nomor 108 Tahun 2019 tentang Kebijakan Strategi Daerah Pengelolaan Sampah Rumah Tangga dan Sampah Sejenis Rumah Tangga.

2. PerGub Provinsi DKI Jakarta Nomor 77 Tahun 2020 tentang Pengelolaan Sampah di Lingkup RW. Melalui PerGub ini, terbentuk Badan Pengelolaan Sampah dan TPS di 24 RW Kepulauan Seribu.

3. PerGub Provinsi DKI Jakarta Nomor 142 Tahun 2019 tentang Penggunaan Kantong Belanja Ramah Lingkungan.

4. Instruksi Gubernur Provinsi DKI Jakarta Nomor 157 tentang Pembentukan dan Pengembangan Bank Sampah.

Total sampah yang dihasilkan di Kepulauan Seribu sebanyak 46,1 ton/hari, yang terdiri dari 17,34 ton/hari sampah rumah tangga dan sejenisnya, 22,46 ton/hari sampah pesisir, serta 6,3 ton/hari sampah laut. Salah satu pulau di Kepulauan Seribu yaitu Pulau Tidung, memiliki TPS seluas $7.000 \mathrm{~m}^{2}$ dan saat ini memiliki 3 RW. Pengambilan sampahnya dilakukan dengan beragam cara yaitu diambil setiap hari (sampah rumah tangga, sampah organik, sampah pesisir), setiap Senin (sampah anorganik bernilai ekonomis), dan setiap Rabu/Kamis setiap 1 bulan (sampah $e$-waste dan sampah $\mathrm{B} 3$ rumah tangga). Alat transportasi yang digunakan untuk mengangkut sampah ke Bantar Gebang adalah 8 kapal sampah mantama, 8 truk sampah, 60 germor, dan gerobak kayu. Jenis pengelolaan sampah di Kepulauan Seribu terdapat beberapa jenis, yaitu:

a) Biokonversi maggot

Biokonversi maggot merupakan alat yang dapat mengelola sampah organik dalam kapasitas rendah menjadi pupuk kompos yang digunakan untuk pertanian non-hidroponik.

b) Teknologi pencacah plastik

Teknologi mesin pencacah plastik merupakan mesin pencacah yang terdiri dari silinder dengan tipe reel dan bedknife. Mesin pencacah tipe reel ini prosesnya kurang efisien karena proses pemotongan lama dan tenaga yang besar, mesin sering tersendat, dan pisau pemotong sering tumpul. 
c) L-Box

L-Box merupakan alat pemusnah sampah dengan metode pembakaran ionisasi dengan suhu sekitar $100-200^{\circ} \mathrm{C}$. jumlah sampah yang dimusnahkan melalui L-Box sekitar 300-1.100 kg/hari. Kapasitas L-Box di Kepulauan Seribu hanya sekitar 1,5 ton karena, ditunjukkan untuk tingkat kelurahan.

d) Teknologi pirolisis

Pirolisis merupakan teknologi pemanasan sampah plastik dalam prosesnya tanpa menggunakan udara. Output yang dihasilkan dalam proses tersebut bahan bakar minyak maupun bahan bakar gas. Minyak yang dihasilkan dari pirolisis dapat digunakan untuk berbagai macam kebutuhan. Untuk penggunaan skala kecil dapat diaplikasikan pada kompor dan minyak tanah

e) Ecobrick

Ecobrick merupakan salah satu metode yang digunakan untuk meminimalisir sampah plastik dengan memadatkan sampah plastik ke dalam botol plastik, sehingga botol tersebut menjadi keras dan padat. Pemanfaatan ecobrick yang telah dilakukan oleh Sudin LH Kepulauan Seribu contohnya menjadi hiasan miniatur kapal di Pulau Tidung. Sampah organik yang berhasil dikurangi melalui proses ecobrick sebesar 0,75-2,00 kg/hari.

Selain jenis pengelolaan sampah, DLH Kepulauan Seribu telah melakukan hubungan kerja sama dengan Lembaga Swadaya Masyarakat (LSM/NGO), baik dalam pengembangan teknologi sampah maupun program edukasi masyarakat sekitar. Bentuk-bentuk kerja sama yang dilakukan dengan LSM/NGO berupa:

a) Divers Clean Action (DCA)

DCA merupakan sebuah yayasan yang memberikan edukasi kepada masyarakat mengenai literasi pemilahan dan pengelolaan sampah di Kepulauan Seribu. Program yang dilakukan oleh DCA seperti : bhay plastik, marine debris rangers, adopsi karang, dan lainnya.

b) Jejak Seribu

Jejak Seribu merupakan komunitas anak muda untuk mengaktifkan edukasi masyarakat di Pulau Tidung mengenai literasi lingkungan dan pemberdayaan masyarakat melalui berbagai program seperti: Tidung Clean Up Action, Jejak Oceana, Festival Pulau Bercerita, dan lain-lain.

c) Astra International dan Indonesia Foundation

PT. Astra International dan Indonesia Foundation melakukan kerja sama dalam pengelolaan sampah plastik yang sudah tidak memiliki nilai ekonomis, melalui pemberian alat teknologi pirolisis. Teknologi ini digunakan untuk mengubah plastik menjadi bahan bakar minyak dan bahan bakar gas yang dapat digunakan untuk aplikasi kebutuhan sehari-hari. Teknologi ini sudah mulai dilaksanakan di Pulau Pramuka dan Pulau Tidung. 


\subsection{Analisis supply chain sampah di Kepulauan Seribu saat pandemi covid-19}

"Banyak yang mengambil pandangan bahwa supply chain bersifat reduksionis dan statis pada rantai pasokannya, yang berakibat tidak memperhatikan kondisi lingkungan kontekstualnya lebih luas" (Wieland 2021). Hal tersebut tidak selalu terjadi jika dapat menyusun strategi supply chain dengan baik. Dalam supply chain sampah di Kepulauan Seribu, terdapat alur dan pengelolaan yang dimulai dari sampah rumah tangga, wisatawan, laut, dan sampah pesisir hingga pengelolaan sampah akhir yaitu TPST Bantar Gebang. Saat pandemi Covid-19, pengelolaan sampah di Kepulauan Seribu tidak memiliki perbedaan yang signifikan dengan sebelum pandemi Covid-19. Hanya terdapat beberapa kegiatan yang lebih diperketat seperti kegiatan pengumpulan sampah yang diperlukan protokol kesehatan dan terhentinya kegiatan pengolahan sampah yang dilakukan warga akibat pembatasan perkumpulan warga.

Berdasarkan data PJLP LH Pulau Tidung, sampah dikelompokkan atas 3 sumber yaitu sampah rumah tangga, sampah pesisir, dan sampah retribusi (Gambar 1). Sampah rumah tangga adalah sampah yang berasal dari kegiatan sehari-hari rumah tangga, tidak termasuk tinja dan sampah spesifik (Damanhuri dan Padmi 2019). Sampah pesisir merupakan sampah yang berada di wilayah peralihan antara daratan dan lautan, sedangkan sampah retribusi merupakan sampah non-rumah tangga yang diangkut oleh PJLP LH dari industri, puskesmas, perkantoran, dan sebagainya. Adapun sampah terbanyak dihasilkan oleh rumah tangga sebesar $77 \%$, diikuti oleh sampah pesisir $21 \%$ dan sampah retribusi $1 \%$.

Ket:

- $\quad$ PJLP LH = Penerimaan Penyedia Jasa Lainnya Orang Perorangan Lingkungan Hidup.

- $\quad$ PPSU = Petugas Penanganan Prasarana dan Sarana Umum.

- $\quad$ TPS $=$ Tempat Penampungan Sementara

- $\quad$ TPST = Tempat Pengolahan Sampah Terpadu.
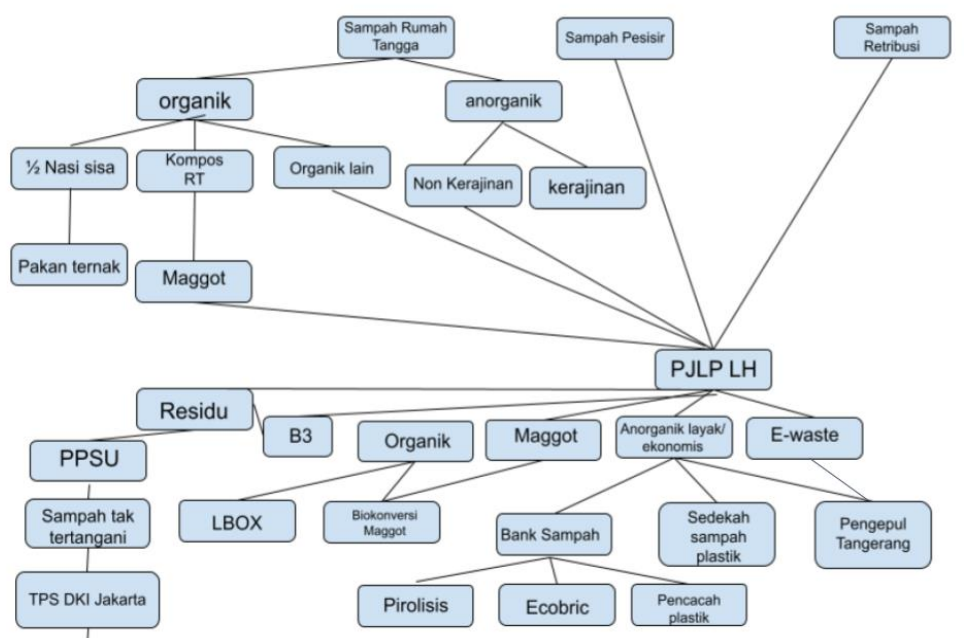

TPST Bantar Gebang

Gambar 1. Supply chain sampah Kepulauan Seribu. 
Supply chain sampah di Kepulauan Seribu yang berasal dari rumah tangga dipilah terlebih dahulu secara mandiri dengan membagi dua jenis sampah yang terdiri dari sampah organik dan anorganik. Daur ulang oleh rumah tangga di mana daur ulang dapat menghindari kemasan plastik, yang sangat penting di pulau-pulau kecil di mana langkah pertama adalah mengurangi volume sampah plastik yang harus dikelola (Assa dan Wibisono 2020).

Pada sampah organik, warga memilah 50\% nasi sisa yang akan disalurkan untuk pakan ternak. Beberapa rumah tangga dengan Kartu Keluarga (KK) prioritas melakukan pengolahan sampah organik secara mandiri yang menghasilkan kompos. Namun masih menyisakan maggot sebagai residu yang akan disalurkan kembali ke Penerimaan Penyedia Jasa Lainnya Orang Perorangan Lingkungan Hidup (PJLP LH) Pulau Tidung bersama dengan 50\% nasi sisa dan sampah organik lainnya yang tidak diolah oleh KK non-prioritas. Di samping pengelolaan sampah organik, terdapat pula pengelolaan sampah anorganik di lingkungan warga. Warga memilah sampah anorganik berdasarkan jenis sampah yang bernilai atau layak untuk dijual ke pengepul, dan sampah yang sudah tidak bernilai, serta beberapa ibu-ibu membuat kerajinan dari sampah anorganik tersebut. Saat Pandemi Covid-19, kegiatan ibu-ibu dalam membuat kerajinan terhenti akibat adanya pembatasan kegiatan perkumpulan, karenanya saat ini kerajinan bahan anorganik tidak lagi dihasilkan. Berdasarkan pengelolaan sampah yang dilakukan warga, rumah tangga telah berhasil mereduksi $19,5 \%$ dari total $77 \%$ sampah rumah tangga.

Petugas PJLP LH mengangkut sampah dari hasil pemilahan rumah tangga, sampah pesisir, dan sampah retribusi. Sampah-sampah yang dikumpulkan dipilah kembali berdasarkan 5 kategori, antara lain sampah organik (32\%), sampah anorganik bernilai (2,5\%), e-waste $(0,2 \%)$, B3 $(0,03 \%)$ dan sampah residu (65\%). Adapun sampah organik akan diolah menggunakan teknologi biokonversi maggot dengan maggot hasil rumah tangga dan L-Box, sedangkan sampah anorganik layak/ekonomis berupa plastik akan ditampung oleh bank sampah dan dihancurkan melalui mesin pencacah plastik yang dilebur hingga menjadi biji plastik, serta mesin pirolisis untuk dikonversi menjadi bahan bakar minyak. Sampah anorganik berupa logam, besi, baja, dan $e$-waste akan dijual ke pengepul yang berada di Tangerang. Kemudian, sampah jenis residu dan B3 tidak dapat tertangani dalam pengelolaannya sehingga akan diangkut oleh petugas Penanganan Prasarana dan Sarana Umum (PPSU). Sampah residu dapat berupa popok, pembalut, merek kemasan, dan sebagainya. Sampah yang tidak tertangani tersebut akan ditampung sementara ke Tempat Penampungan Sementara (TPS) DKI Jakarta dan berakhir ke Tempat Pengolahan Sampah Terpadu (TPST) Bantar Gebang. 
Saat ini, Kondisi landfill TPST Bantar Gebang mencapai ketinggian 47-50 meter dengan batas maksimum 57 meter, serta luas lahan 110,3 ha. Teknologi pengelolaan sampah yang digunakan TPST Bantar Gebang adalah incinerator. Teknologi ini digunakan untuk membakar sampah dengan temperatur tinggi. Insinerasi material sampah mengubah sampah menjadi abu, gas sisa hasil pembakaran, partikulat, dan panas.

\subsection{Model dan strategi pengelolaan dan pengolahan sampah yang efektif di Kepulauan Seribu}

Pengelolaan dan pengolahan sampah yang ada di Kepulauan Seribu sudah tersedia dan berjalan dengan baik. Pada saat pandemi Covid-19 tidak ada perubahan dalam sistem tata kelolanya, namun hanya saja dilakukan dengan protokol kesehatan yang ketat dari setiap pengelola. Kondisi pengelolaan sampah di Kepulauan Seribu dapat dianalisis menggunakan matriks analisis SWOT. Teknis analisis SWOT merupakan teknik dasar untuk mengetahui berbagai kondisi untuk perencanaan suatu strategi (Jazuli 2016). Analisis SWOT digunakan untuk mengevaluasi kekuatan (strengths), kelemahan (weakness), peluang (opportunities), dan ancaman (threats) dalam menentukan model dan strategi pengelolaan dan pengolahan sampah yang efektif di Kepulauan Seribu (Fatimah 2016). Kekuatan adalah faktor yang mendukung peluang dan mengatasi ancaman. Kelemahan merupakan faktor yang mengakibatkan tidak mampu memanfaatkan peluang. Peluang merupakan faktor yang membantu mengembangkan dan timbul dari berbagai sumber. Sedangkan ancaman merupakan faktor yang terdiri dari berwujud atau tidak berwujud yang dapat menimbulkan dampak negatif dalam pembentukan suatu strategi (Sarsby 2016). Diagram matriks analisis SWOT (Gambar 2) menunjukkan bahwa kondisi pengelolaan sampah di Kepulauan Seribu berada pada kuadran I.

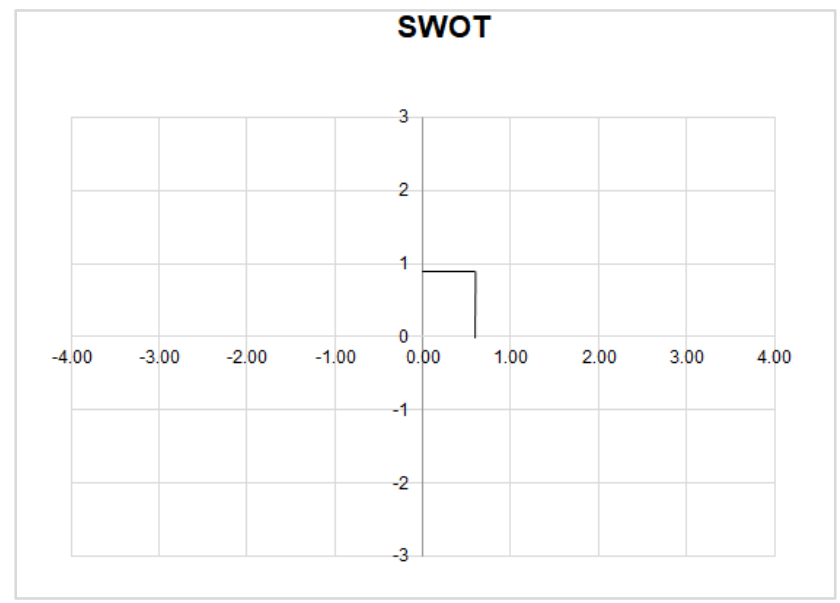

Gambar 2. Diagram analisis SWOT. 
Hal ini dapat diartikan bahwa pengelolaan tersebut mendukung strategi yang agresif. Strategi agresif sangat berpotensi untuk dikembangkan karena memiliki peluang dan kekuatan yang positif. Agresivitas ditunjukkan dengan sudah adanya kebijakan tata kelola sampah yang baik, adanya kerja sama antara Pemerintah Kabupaten Kepulauan Seribu dengan LSM atau NGO yang peduli terhadap pengelolaan sampah yang terintegrasi sehingga pemerintah dengan NGO dapat berkolaborasi dalam penanganan sampah di Kepulauan Seribu, serta sudah adanya pemilahan sampah di tingkat rumah tangga sehingga memudahkan para pengelola sampah. Situasi ini sangat menguntungkan karena memiliki peluang dan kekuatan sehingga dapat memanfaatkan kesempatan yang sudah tersedia (Rangkuti 2019). Strategi yang harus diterapkan dalam kondisi ini adalah mendukung kebijakan pertumbuhan yang agresif (growth oriented strategy) ataupun dengan rekomendasi strategi progresif, artinya tata kelola sampah di Kepulauan Seribu sudah dalam kondisi yang baik sehingga sangat memungkinkan untuk terus melakukan pengelolaan sampah dengan melakukan peningkatan strategi pengelolaan sampah dan meraih kemajuan secara maksimal karena peluang sudah terbuka. Berdasarkan hasil analisis matriks SWOT, dapat dikembangkan beberapa alternatif strategi yang sesuai dengan kondisi tata kelola sampah di Kepulauan Seribu yang dijelaskan pada bagian selanjutnya.

\subsubsection{Strategi SO}

Berdasarkan hasil analisis matriks SWOT, alternatif strategi SO yang dihasilkan yaitu melakukan kegiatan sosialisasi tidak hanya untuk rumah tangga prioritas, namun kepada seluruh warga di Kepulauan Seribu. Kemudian strategi yang harus diperkuat adalah merealisasikan kebijakan tugas BPS (Bidang Pengelolaan Sampah) di tingkat RW seperti yang sudah tercantum dalam PerGub Provinsi DKI Jakarta Nomor 77 Tahun 2020. Alternatif strategi lainnya yaitu meningkatkan ketersediaan dana untuk pengelolaan sampah di Kepulauan Seribu.

\subsubsection{Strategi WO}

Berdasarkan matriks SWOT, alternatif strategi yang dihasilkan yaitu menerapkan sanksi bagi warga di Kepulauan Seribu yang membuang sampah tidak pada tempatnya. Strategi lain yang dapat dilakukan yakni meningkatkan teknologi yang dapat mengurangi sampah sehingga berdampak pada berkurangnya penggunaan alat transportasi untuk mengirim sampah ke TPST Bantar Gebang. Selanjutnya dapat mengadakan kerja sama antar pemerintah, warga dengan NGO agar sampah tidak hanya dikirimkan ke Bantar Gebang, namun dapat diolah di Kepulauan Seribu atau dikirim ke tempat lain selain Bantar Gebang. 


\subsubsection{Strategi ST}

Alternatif strategi pengembangan pengelolaan yang dihasilkan dari matriks SWOT adalah menguatkan pengelolaan sampah di wilayah hulu yaitu bagian barat dan timur, agar saat terjadi angin barat dan angin timur tidak menyebabkan penumpukan sampah di Kepulauan Seribu akibat sampah kiriman dari hulu. Kemudian membuat kebijakan pembatasan jumlah wisatawan yang berkunjung untuk pengurangan sampah. Memberikan kemudahan akses bagi para pengelola sampah saat pandemi Covid-19 dan menyediakan teknologi yang ramah lingkungan. Selain itu strategi yang dapat diterapkan yaitu menambah sumber dana selain dari pemerintah berupa penjualan hasil olahan sampah.

\subsubsection{Strategi WT}

Alternatif strategi WT yang dapat diterapkan yakni membuat bank sampah induk di setiap RT di Kepulauan Seribu agar tidak semua sampah dikirim ke Bantar Gebang. Kemudian dapat mengadakan sosialisasi kepada pengelola sampah untuk meyakinkan para warga agar bersedia berkontribusi menjadi pengurus pengiriman sampah ke TPST Bantar Gebang saat pandemi Covid-19. Strategi lain yaitu membuat papan pengumuman mengenai peraturan pembuangan sampah di setiap tempat wisata dan menyediakan tong sampah di seluruh wilayah Kepulauan Seribu. Selain itu, pemerintah dapat menyediakan tempat pengelolaan sampah yang layak jual di sekitar tempat wisata, sehingga menghasilkan barang atau kerajinan yang bernilai ekonomis dengan tujuan mengurangi sampah yang berasal dari wisatawan dan warga sekitar.

\section{KESIMPULAN DAN SARAN}

\subsection{Kesimpulan}

1. Kondisi tata kelola sampah di Kepulauan Seribu selama pandemi Covid-19 tidak jauh berbeda dengan sebelum pandemi. Hanya saja terdapat penurunan jumlah sampah, namun sampah kiriman justru semakin meningkat karena adanya faktor cuaca.

2. Alur tata kelola sampah di Kepulauan Seribu dari hulu hingga ke hilir sudah berjalan dengan baik, hanya perlu penguatan pada kebijakan yang sudah ada agar tidak terjadi hambatan dalam proses pengiriman sampah ke TPST Bantar Gebang. Namun, kondisi TPST Bantar Gebang saat ini hampir overload, maka perlu adanya pengurangan jumlah sampah dari Kepulauan Seribu.

3. Berdasarkan hasil analisis SWOT, kondisi pengelolaan sampah di Kepulauan Seribu berada pada kuadran I, artinya pengelolaan mendukung strategi yang agresif. Agresivitas ditunjukkan dengan sudah adanya berbagai kebijakan dan tata aturan yang tertulis dari pemerintah untuk pengelolaan sampah, dan lebih dari 50\% masyarakat telah memilah sampah berdasarkan jenisnya. 


\subsection{Saran}

1. Untuk mengurangi jumlah sampah kiriman di laut akibat adanya faktor cuaca seperti angin barat dan angin timur diperlukan adanya strategi pengelolaan yang baik seperti tidak boleh membuang sampah di sekitar pesisir Teluk Jakarta agar ketika terjadinya perubahan cuaca tidak menyebabkan penumpukan sampah di Kepulauan Seribu.

2. Diperlukan penguatan peran Bidang Pengelolaan Sampah (BPS) sesuai dengan Peraturan Gubernur No. 77 Tahun 2020 mengenai pengelolaan sampah di lingkup Rukun Warga (RW). Selain itu pemerintah dapat menambah jumlah bank sampah di masing-masing Rukun Tetangga (RT) dan memastikannya berjalan dengan lancar, kemudian dapat dengan cara mencegah penumpukan sampah di sungai-sungai yang ada di Jakarta, serta dengan meningkatkan kapasitas teknologi penghancur sampah, namun tetap di bawah ambang batasnya.

3. Untuk meningkatkan efisiensi pengelolaan sampah dan mereduksi jumlah sampah di Kepulauan Seribu, diperlukan peningkatan kerja sama antar Pemerintah Daerah Kabupaten Kepulauan Seribu dengan perusahaanperusahaan yang memproduksi barang konsumsi masyarakat agar sampah saat pandemi Covid-19 di Kepulauan Seribu dikembalikan dan diolah oleh perusahaan tersebut. Bentuk kerja sama lain juga dapat dilakukan dengan pemberian teknologi ataupun alat yang mampu mereduksi timbulan sampah tanpa merusak kondisi lingkungan.

\section{UCAPAN TERIMAKASIH}

Ucapan terima kasih kepada Kementerian Pendidikan dan Kebudayaan Republik Indonesia yang telah membiayai penelitian ini. Terima kasih juga kepada Institut Pertanian Bogor, Fakultas Ekonomi dan Manajemen, dosen pendamping, dosen reviewer IPB yang telah memfasilitasi tim peneliti dan banyak memberi arahan dalam penyelesaian penelitian ini. Dosen-Dosen Fakultas Ekonomi dan Manajemen, IPB University

\section{DAFTAR PUSTAKA}

Agamuthu P, Mehran S, Norkhairah A dan Norkhairiyah A. 2019. Marine debris: a review of impacts and global initiatives. Waste Management \& Research 37(10):987-1002. https://doi.org/10.1177/0734242x19845041.

Assa AF dan Wibisono C. 2020. Waste treatment management for shores and ocean cleanness in Pari Island, Indonesia. Utopia y Praxis Latinoamericana 25(10):197-207. https://doi.org/10.5281/zenodo.4155491. 
Baidowi A, Santoso A, Hatori C A, Sianturi D S A, Purwanto D A, Hartono D R B, Prabawa F Y, Elida F, Chandra H, Triwibowo H, Radiarta I N, Marzuki M I, Ananda M I, Syamsiro M, Kusumaningrum P D, Gruning R O S, Ricky, Rahmania R, Akhwady R, Febri S P dan Firdaus T Y. 2020. Realita dan rekomendasi pengelolaan sampah di kepulauan. IPB Press. Bogor.

[BPS] Badan Pusat Statistik Kabupaten Kepulauan Seribu. 2021. Kabupaten Kepulauan Seribu dalam angka 2021. BPS Kabupaten Kepulauan Seribu. Kepulauan Seribu.

Damanhuri E dan Padmi T. 2019. Pengelolaan sampah terpadu. ITB Press. Bandung.

Fatimah FND. 2016. Teknik analisis SWOT. Anak Hebat Indonesia. Yogyakarta.

Instruksi Gubernur Provinsi DKI Jakarta Nomor 157 tentang pembentukan dan pengembangan bank sampah.

Jazuli S. 2016. Analisis SWOT strategi pemasaran produk pembiayaan pada BMT El-Syifa Ciganjur [Tesis]. Jurusan Ilmu Dakwah, Fakultas Ilmu Dakwah dan Ilmu Komunikasi, Universitas Islam Negeri Syarif Hidayatullah. Jakarta.

Kholil A, Budiaman, Mirtawati dan Jumhur AA. 2018. Waste management based on 3R in mutiara waste banks Bekasi City Indonesia. World Environment 8(3):71-76.

PerDa (Peraturan Daerah) Provinsi DKI Jakarta Nomor 13 Tahun 2013 tentang pengelolaan sampah.

PerDa (Peraturan Daerah) Provinsi DKI Jakarta Nomor 4 Tahun 2019 tentang perubahan atas PerDa Provinsi DKI Nomor 13 Tahun 2013 tentang pengelolaan sampah.

PerGub (Peraturan Gubernur) Provinsi DKI Jakarta Nomor 108 Tahun 2019 tentang kebijakan strategi daerah pengelolaan sampah rumah tangga dan sampah sejenis rumah tangga.

PerGub (Peraturan Gubernur) Provinsi DKI Jakarta Nomor 142 Tahun 2019 tentang penggunaan kantong belanja ramah lingkungan.

PerGub (Peraturan Gubernur) Provinsi DKI Jakarta Nomor 77 Tahun 2020 tentang pengelolaan sampah di lingkup rukun warga.

Premakumara DGJ, Abe M and Maeda T. 2011. Reducing municipal waste through promoting integrated sustainable waste management (ISWM) practices in Surabaya City, Indonesia. Ecosystems and Sustainable Development VIII 144: 457-468. https://doi.org/10.2495/eco110401.

Putri AP, Sandra FR, Afla KA, Setyani NW, Vidyatama SR and Putra VBK. 2020. Good and systematic waste management efforts in Bantar Gebang through cooperation between DKI Jakarta Provincial Government and Bekasi City Government [internet]. Tersedia di: https://www.researchgate.net/ publication/352560312_GOOD_AND_SYSTEMATIC_WASTE_MANAGEMEN 
T_EFFORTS_IN_BANTAR_GEBANG_THROUGH_COOPERATION_BETWEEN_ DKI_JAKARTA_PROVINCIAL_GOVERNMENT_AND_BEKASI_CITY_GOVERN MENT.

Rangkuti F. 2019. Teknik membedah kasus bisnis analisis SWOT cara perhitungan bobot, rating, dan OCAI. PT. Gramedia Pustaka Utama. Jakarta.

Sahwan FL. 2004. Strategi pengelolaan sampah di kawasan Kepulauan Seribu. Jurnal Teknologi Lingkungan 5(1).

Sarsby A. 2016. SWOT analysis. The Leadership Library. UK.

Skenderovic I, Kalac B and Becirovic S. 2015. Environmental pollution and waste management. Balkan Journal of Health Science 3(1):2-10.

Suhada R and Al-Mahdy I. 2020. Waste potential analysis as a source of electrical power plant and creative product to support tourism (case study in Kepulauan Seribu). Scientific Journal of PPI-UKM 7(2):2356-2536.

Wieland A. 2021. Dancing the supply chain: toward transformative supply Chain management. Journal of Supply Chain Management 57(1):58-73. 